Kimi Kärki

\title{
Kasarihevin liveylistys
}

FT, dosentti Kimi Kärki on erikoistutkija Turun yliopiston kulttuurihistorian oppiaineessa ja International Institute for Popular Culture (IIPC) -tutkimuskeskuksessa. Hän johtaa tutkimushanketta Fasismin lumo ja affektiivinen perintö suomalaisessa kulttuurissa (Koneen Säätiö 2021-2023). Hän on erikoistunut populaarikultturin historiaan, erityisesti populaarimusiikin kulttuuriperintöön ja on julkaissut muun muassa stadionrockin historiasta, elokuvista, tulevaisuuden kuvittelusta, urheilun estetiikasta sekä puhuvista koneista. Hän on myös yli neljäkymmentä levytystä julkaissut kitaristi ja laulaja-lauluntekijä, jolla on runsaasti kansainvälistä kiertuekokemusta.

DOI: https://doi.org/10.51816/musiikki.111762 


\section{Kasarihevin liveylistys}

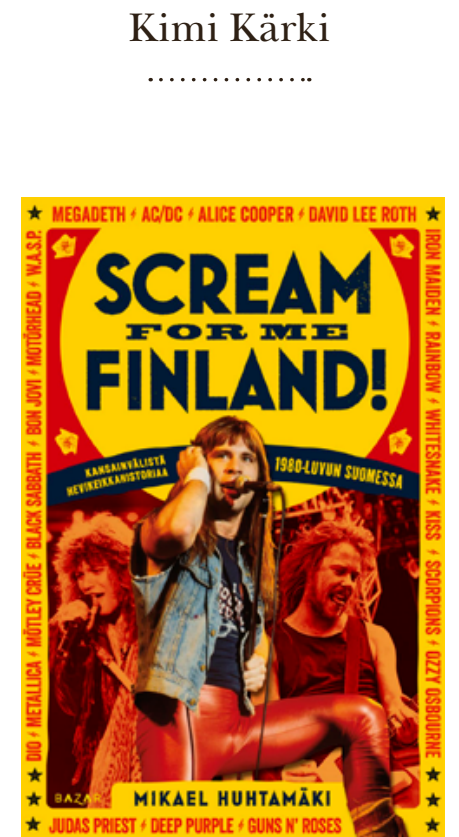

Huhtamäki, Mikael 2020.

Scream for Me Finland!

Kansainvälistä hevikeikkahistoriaa 1980-luvun Suomessa.

Helsinki: Bazar Kustannus Oy.

368 sivua.

Populaarimusiikin keikkahistoriasta ei ole suomeksi kirjoitettu riittävästi, jos ei suoria artistibiografioita oteta huomioon. Siksi tartuinkin ilolla tähän ajankuvaan. Eri yhteyksissä "tavalliseksi musadiggariksi" ja "entiseksi teinihevariksi" esitelty Mikael Huhtamäki on itse aiemmin kirjoittanut vastaavan kirjan kansainvälisten yhtyeiden keikoista Suomessa vuosina 1955-1979. Viime vuonna ilmestyneessä kirjassaan Scream for me Finland! hän on tarttunut selvästi rakkaaseen aiheeseen lähdettyään kartoittamaan nimenomaan 1980-luvun kansainvälisiä hevikeikkoja Suomessa. Tuhti kovakantinen kirja onkin kohteensa näköinen: keskellä kantta poseeraa mikrofonin varressa itseoikeutetusti kirjan nimen ikonisella 
huudollaan inspiroinut Iron Maidenin laulaja Bruce Dickinson. Tämän farkkuliivi, hiusten mullet-leikkaus ja haaroista pullistuvat punaiset nahkahousut eivät jätä mitään arvailujen tai sattuman varaan. Muutenkin kirjan kuvitus on ensiluokkaista: mustavalkokuvien lisäksi kaksi 16-sivuista värikuvaliitettä takaavat, että olennainen välittyy. Kirjan kohteena onkin yksi visuaalisesti tunnistettavimmista, rakastetuimmista, vihatuimmista, ironisoiduista ja teatraalisimmista elävän musiikin tyylilajeista. 1980-luvun aikana heviyhtyeet itse pitivät huolen spektaakkeliensa huolellisista ylilyönneistä - Rob Reinerin fiktiivisestä heviyhtyeestä tekemä elokuva Spinal Tap (1984) tuntuu tätäkin kirjaa lukiessa aidolta ja jopa vähän kesyltä aikalaisdokumentilta.

Kirjan käsittelemät yhtyeet ovat kuin kasarihevin kuka kukin on: kirjan luvuissa esiintyvät Iron Maiden, Rainbow, Motörhead, Whitesnake, Ozzy Osbourne, Scorpions, Black Sabbath, Dio, KISS, W.A.S.P, Mötley Crüe, Metallica, Bon Jovi, AC/DC, Judas Priest, Deep Purple, Megadeth, David Lee Roth, Alice Cooper ja Guns N' Roses. Tämä listaus on myös yhtyeiden käsittelyjärjestys, mikä ensi alkuun ihmetyttää, kun joukossa on monia jo 1970-luvulla aloittaneita yhtyeitä - Alice Cooper, Black Sabbath ja Deep Purple itse asiassa levyttivät peräti jo 1960-luvun puolella. Logiikka tässä on se, että järjestys määräytyy kunkin ensimmäisen 1980-luvun Suomen keikan mukaan. Kirjan lopussa on vielä listattu muitakin Suomessa 1980-1991 esiintyneitä heviyhtyeitä; päälukuihin valitut yhtyeet varmasti edustavat Huhtamäen näkemystä kovimmista livebändeistä. Toisaalta myös tarjolla olleen dokumentaation määrä on voinut vaikuttaa valintoihin.

Tarinat ja detaljit ovat viihdyttäviä ja usein nyttemmin myötähäpeää ja jopa inhoa aiheuttavia: tuttua osastoa oli esimerkiksi Deep Purple -vokalisti Ian Gillanin pistäytyminen Black Sabbathin laulajana 1983 ja "Paranoidin" sanoituksen lunttaaminen muistilapuilla kesken keikan, samoin Törkytehdas-kirjastakin (2012) tutut Mötley Crüen seksistiset ja viinanhuuruiset bileet. Toisaalta lapualaisen nuoren Jarin bilettäminen Ronnie James Dion kanssa ja tämän Dio-yhtyeen hotellihuoneen haltuunotto Hesperiassa yhtyeen jatkettua matkaansa tuo sympaattista lisäväriä bändin meininkiin. Heidän 300000 dollaria maksaneeseen lavarakennelmaansa kuului sittemmin, vuonna 1986, "jylhä keskiaikainen linna, kuusimetrinen lohikäärme, ritarirobotti, kristallipallo, lasereita, tulipatsaita ja vaikka mitä" (s. 148). Esimerkiksi jalkojen väliin sijoitetuista sirkkelinteristään tunnetun W.A.S.P.-yhtyeen tyypillisen raa'an lihan heittelyn ja ennen muuta pääkallosta juodun veren jäljiltä taas jäi Orwellin vuonna 1984 helsinkiläisen Lepakon lautalattiaan jälki, joka pysyi siinä 1990-luvun re- 
monttiin asti. Paikan talonmies muisteli myös salin takanurkkaan sijoittautuneita uskovaisia, jotka rukoilivat ja manasivat pois pahoja henkiä.

Kirjan vahvuudet ja heikkoudet ovat oikeastaan samoja, eli sen kronikoiva ote ja todella pitkät sitaatit alkuperäismateriaaleista. Kirja on ikään kuin luuppi, silmukka, joka etenee yhtye kerrallaan läpi kunkin yhtyeen esiintymishistorian Suomessa 1980-luvulla. Käytännössä tarinan keskiössä ovat lavarakennelmien muutos hevin suosion lisääntyessä sekä esiintymisten multimodaalisesta aineistosta koostettu kuvaileva kertomus huippuhetkistä, spektakulaarisista lavarakennelmista, pyrotekniikasta, asuista, yleisön huudatuksista - joiden kohdalla tarkassa litteroinnissa tulee itse asiassa hiukan etnografian fiilistä - ja keikkojen kappalejärjestyksistä. Kuvailun ylittävää analyysia tulee varsin vähän, eikä tapahtumia juuri sijoiteta aikalaisyhteyksiinsä. Mutta sitaatit kuljettavat lukijan aikakoneella Reaganin ajan Yhdysvaltoja ja Thatcherin Englantia ihailevan pimeän ja kylmän maailmankolkan nuorten fantasioihin, takahuonepassia toivovien tyttöjen odotuksiin ja maskuliinisen uhon, romantiikan ja soturimytologioiden täyttämien teinihevareiden alati taistelevaan mielenmaisemaan. Lopulta jäljelle jäävät nostalgiset muistot ja niiden kierrättäminen.

Pääosassa ovat ennen muuta journalistiset lähteet: Huhtamäki on käynyt tarkasti läpi oletettavasti kaikki käsiteltävien yhtyeiden kasarikeikoista tehdyt lehtijutut. Näiden ydin on siteerattu läpi aika lailla sellaisenaan. Tämä tekee Huhtamäestä eräänlaisen tekstikuraattorin, joka tarjoilee journalistien ja fanien keikkakuvausten ja tallenteiden mehukkaat parhaat palat lukijalle ja höystää näitä omilla huomioillaan ennen muuta lyhyissä lukujen alun introissa.

Tästä alkutekstien ehdoilla kulkemisesta seuraa kaksi asiaa: Huhtamäen oma ääni katoaa välillä miltei kokonaan, liikkuminen sitaattien välillä on lähes saumatonta. Mutta tämä ei ole akateeminen kirja, joten tässä tapauksessa keskityn toisaalta ratkaisun hyvään puoleen: kirjan retoriikka on itsessään täydellinen ajankuva suomalaisesta rocklehdistöstä, faneista, promoottoreista ja itse kansainvälisistä artisteista ja heidän tavastaan muistella menneitä ja välillä mytologisoida toimintaansa. Juuri artistien haastatteluista avautuu lähes epätodellinen ulkopuolisuuden, todellisuudesta usein hiukan vieraantuneen tähden ja tätä ympäröivän koneiston tuottama näkökulma suomalaisiin areenoihin, lavakulttuuriin, pimeisiin metsiin, juhliin, tyttöihin, kolareihin ja elefantinomaisiin hirvihavaintoihin. Toisaalta Huhtamäki on haastatellut ison joukon suomalaisia keikkajärjestäjiä, faneja ja muita toimijoita. Kirjan lopussa on oma lukunsa liittyen bändäritoimintaan, johon onkin saatu kiinnostavaa näkökulmaa 
nimenomaan haastatteluaineiston kautta. Toiminta on ollut niin kyynistä kuin viatonta, ja paljon jätetään epäilemättä myös sanomatta.

Tämä kirja on hyvä ajankuva, taltiointi populaarimusiikkifantasioista ja niitä kaipaavista nuorista. Tekijä on ilmeisesti siirtynyt väitöskirjan pariin, joten jäämme mielenkiinnolla odottamaan häneltä myös analyyttisempaa otetta aineistoihinsa. 